\title{
Difference of Chemical Bonds Between UDMA Bonding Agents with Ethanol Solvent and Acetone Solvent on Dentin Collagen
}

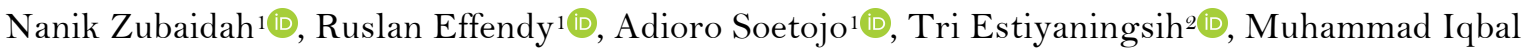 \\ Tanzil2(10, Khusnul Khotimah²(10)
}

${ }^{1}$ Department of Conservative Dentistry Faculty of Dental Medicine, Universitas Airlangga, Surabaya, Indonesia.
${ }^{2}$ Conservative Dentistry Specialist Program, Faculty of Dental Medicine Universitas Airlangga, Surabaya, Indonesia.

Correspondence: Nanik Zubaidah, Department of Conservative Dentistry, Faculty of Dental Medicine, Campus A Universitas Airlangga, Jl. Mayjen Prof. Dr. Moestopo No.47, Surabaya 60132, Indonesia. E-mail: nanik-z@fkg.unair.ac.id

Academic Editor: Catarina Ribeiro Barros de Alencar

Received: 02 June 2020 / Review: 11 September 2020 / Accepted: 21 September 2020

How to cite: Zubaidah N, Effendy R, Soetojo A, Estiyaningsih T, Tanzil MI, Khotimah K. Difference of chemical bonds between UDMA bonding agents with ethanol solvent and acetone solvent on dentin collagen. Pesqui Bras Odontopediatria Clín Integr. 202 1; $21:$ e0116. https://doi.org/10.1590/pboci.2021.030

\begin{abstract}
Objective: To investigate the difference of chemical bonds between urethane dimethacrylate (UDMA) bonding agents with ethanol solvent and acetone solvent on dentin collagen. Material and Methods: This experimental comparison study used three groups: G1 (Control): UDMA and collagen; G2: UDMA, collagen and ethanol; and G3: UDMA, collagen and acetone. The groups were then pelleted and analysed with FTIR, then the peak value of carbonyl absorption band from each study group was calculated. The result of FTIR analysis and the peak of carbonyl absorption band $(\mathrm{P})$ was calculated using the formula: $\mathrm{P}=$ $(\mathrm{BC} / \mathrm{AB}) \mathrm{X} 100 ; \mathrm{AB} . \mathrm{BC}$ is measured in centimeters. The study of chemical bond differences between ethanol-solvent UDMA agents compared with acetone-solvent on dentin collagen resulted in a graph of peak of carbonyl absorption bands of UDMA and dentin collagen groups. To determine the chemical bonds of UDMA from the top of the carbonyl ester absorption bands with wavenumber absorption in range 1700$1750 \mathrm{~cm}-1$, the decreasing peak of the carbonyl absorption bands is assumed as more chemical bonds that formed. Data were analysed using Anova one way and Tukey HSD test. Results: There were significant differences between the three study groups $(\mathrm{p}<0.05)$. Conclusion: UDMA bonding agents' chemical bonds with acetone solvent are much higher than the chemical bonds between UDMA bonding agents with ethanol solvent on dentin collagen.
\end{abstract}

Keywords: Dental Materials; Dental Bonding; Dentin; Dentin-Bonding Agents. 


\section{Introduction}

Composite resin restoration material is being developed continuously, specifically in terms of aesthetics, usage and manipulation, to improve the bonding of composite resins to the dentin [1]. The attachment of composite restoration to dentin requires a bonding agent that works in two ways, namely forming mechanical bonds through the enamel tags formed by etch and building hybrid layer on dentin to form a chemical bond. A chemical bond is formed between the composite resin and the hydroxyapatite on dentin [1]. Despite the development of adhesive system, the least weak area of the restoration remains the bonded interface, and one of the factors that play a role in composite restoration is dentin bonding [2].

Urethane dimethacrylate (UDMA) is one of the methacrylate derivatives that is frequently used as a bonding agent. UDMA has good properties, such as low viscosity, perfect flexibility and good endurance intraoral due to its ability to inhibit transesterification. UDMA-based composites have low water-absorbing characteristics and low solubility [3,4]. The chemical bonds of the UDMA contained in the factory packaging have been previously investigated [5]. Shin et al. [6] also conducted a survey about the influence of hydrophobic monomers on ethanol solvents.

The solvent contained in the bonding material denotes the key agent in forming dentin and resin interfaces. The solvent plays a role in carrying resin monomer molecules into the dentin tubule. The substances commonly used as a solvent in dentin bonding agents are acetone, ethanol or water. Acetone and ethanol have different physical and chemical characteristics, which naturally affect the bond strength of the dentine bonding material [7-9].

This research is based on the existence of several phenomena, potentially causing composite restoration failure. To date, there has been no specific research about the effect of ethanol and acetone solvent toward the chemical bond strength of bonding agent, pure UDMA. Therefore, we aim to investigate the difference of chemical bonds between UDMA bonding agents with ethanol solvent and acetone solvent on dentin collagen $[5,6]$.

\section{Material and Methods}

This study used pure UDMA agents (Sigma Aldrich, St. Louis, Missouri, USA), pure bovine collagen Type 1 (Sigma Aldrich, St. Louis, Missouri, USA), ethanol 98\% (Smart Lab Indonesia, Surabaya, Indonesia), acetone 98\% (Smart Lab. Indonesia, Surabaya, Indonesia) and KBr powder as materials, and using tools: Jasco FTIR 5300, Mortal and Pastel, Kbr die, Presses, Balance Sheet and Micro Pipette.

\section{Experimental Procedure}

Group I (Control)

An amount of $2 \mathrm{mg}$ collagen is added with $10 \mu \mathrm{l}$ pure UDMA and potassium bromide powder $(\mathrm{KBr})$ until the weight reaches $311.1 \mathrm{mg}$, then ground with mortar and pestle until it becomes a homogenous mixture. The mixture is taken $50 \mathrm{mg}$ and blended into $\mathrm{KBr}$ die and then compressed with a 10-ton compressing machine for 5-10 minutes to make clear pellets (thin tablet-shaped). $\mathrm{KBr}$ is used as the background matrix because it is IR transparent due to the plasticity of its alkali halides [10]. Then these pellets are observed with the FTIR tool.

Group II (Ethanol) 
An amount of $2 \mathrm{mg}$ collagen is added with $10 \mu \mathrm{l}$ pure UDMA (weight $11.1 \mathrm{mg}$ ) and potassium bromide powder $(\mathrm{KBr})$ until the weight reaches $311.1 \mathrm{mg}$, then add $20 \mu \mathrm{l}$ ethanol. All ingredients are mixed and grinded with mortar and pestle until it becomes a homogeneous mixture. Furthermore, $50 \mathrm{mg}$ of mixture was taken and blended into $\mathrm{KBr}$ die and compressed with a 10-ton compressing machine for 5-10 minutes to make clear pellets (thin tablet-shaped). These pellets are then observed with the FTIR tool.

\section{Group III (Acetone)}

An amount of $2 \mathrm{mg}$ collagen is added with $10 \mu \mathrm{l}$ pure UDMA (weight $11.1 \mathrm{mg}$ ) and potassium bromide powder $(\mathrm{KBr})$ until the weight reaches $311.1 \mathrm{mg}$, then add $20 \mu \mathrm{l}$ acetone. All ingredients are mixed and crushed with mortar and pestle until it becomes a homogeneous mixture. Furthermore, $50 \mathrm{mg}$ of mixture was taken and blended into $\mathrm{KBr}$ die and compressed with a 10-ton compressing machine for 5-10 minutes to make clear pellets (thin tablet-shaped). These pellets are then observed with the FTIR tool.

The result of FTIR analysis and the peak of carbonyl absorption band $(\mathrm{P})[11,12]$ is calculated using the following formula: $\mathrm{P}=(\mathrm{BC} / \mathrm{AB}) \mathrm{X} 100$; $\mathrm{AB}$. $\mathrm{BC}$ is measured in centimeters. This calculation is accurate and reliable if the absorption band's intensity in ranged $\mathrm{T}: 30-60$.

The study of chemical bond differences between ethanol-solvent UDMA agents compared with acetone-solvent on dentin collagen resulted in a graph of peak of carbonyl absorption bands of UDMA and dentin collagen groups (Figure 1). To determine the chemical bonds of UDMA from the top of the carbonyl ester absorption bands with wavenumber absorption in range $1700-1750 \mathrm{~cm}^{-1}$, the decreasing peak of the carbonyl absorption bands is assumed as more chemical bonds that formed.

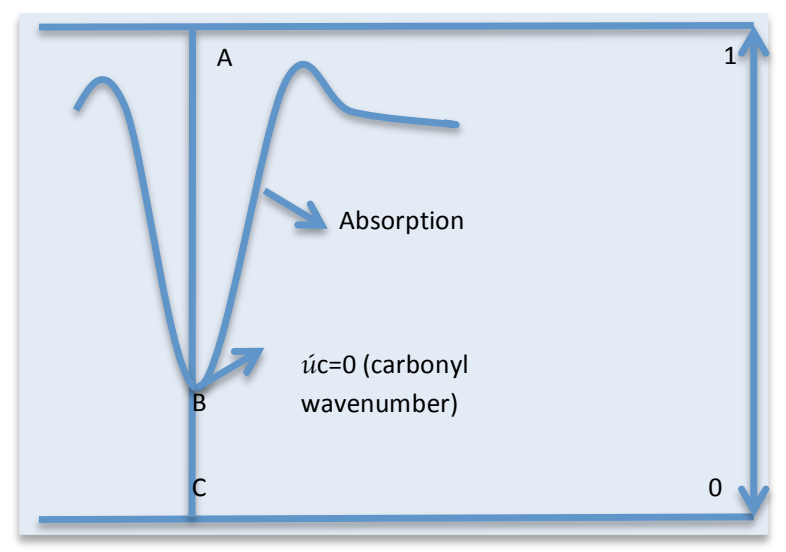

Figure 1. Peak of carbonyl absorption bands of UDMA

Data Analysis

The obtained data is a peak of carbonyl absorption bands (P) that is analysed by normality test by using Kolmogorov-Smirnov and homogeneity test by using Levene test method. Comparative test for data analysis using One Way ANOVA test when data normally distributed and followed by Tukey HSD.

\section{Results}

Figure 2 shows the peak of carbonyl ester absorption bands of UDMA at wavelength absorption 1720 $\mathrm{cm}^{-1}$, the peak of carbonyl absorption bands $(\mathrm{P})$ is calculated using the following formula: $\mathrm{AB}=50 ; \mathrm{BC}=50 ; \mathrm{P}$ $=\mathrm{BC} / \mathrm{AB} \times 100=50 / 50 \times 100=100$. 


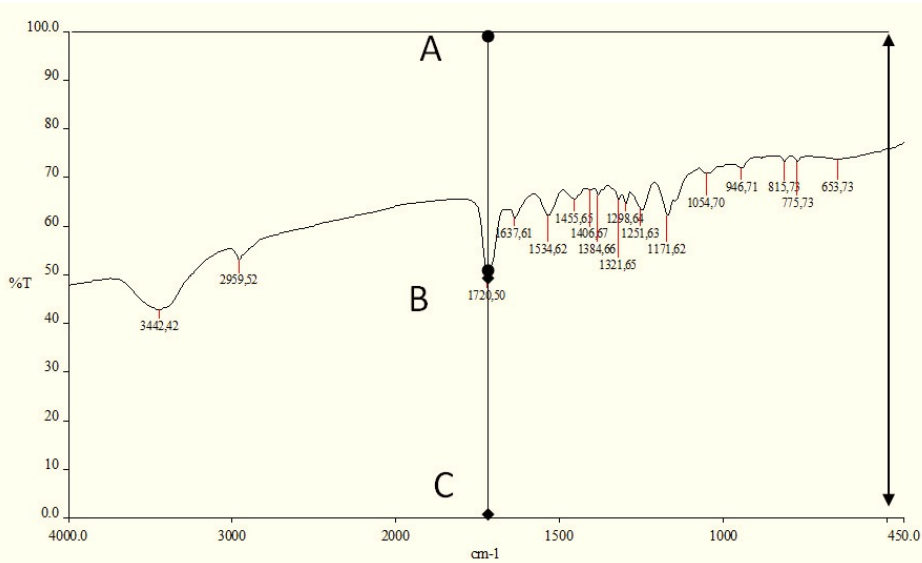

Figure 2. Results of UDMA and collagen.

Figure 3 shows the peak of carbonyl ester absorption bands of UDMA at wavelength absorption 1720 $\mathrm{cm}^{-1}$, the peak of carbonyl absorption bands $(\mathrm{P})$ is calculated using the following formula: $\mathrm{AB}=33 ; \mathrm{BC}=67 ; \mathrm{P}$ $=\mathrm{BC} / \mathrm{AB} \times 100=33 / 67 \times 100=49.25$.

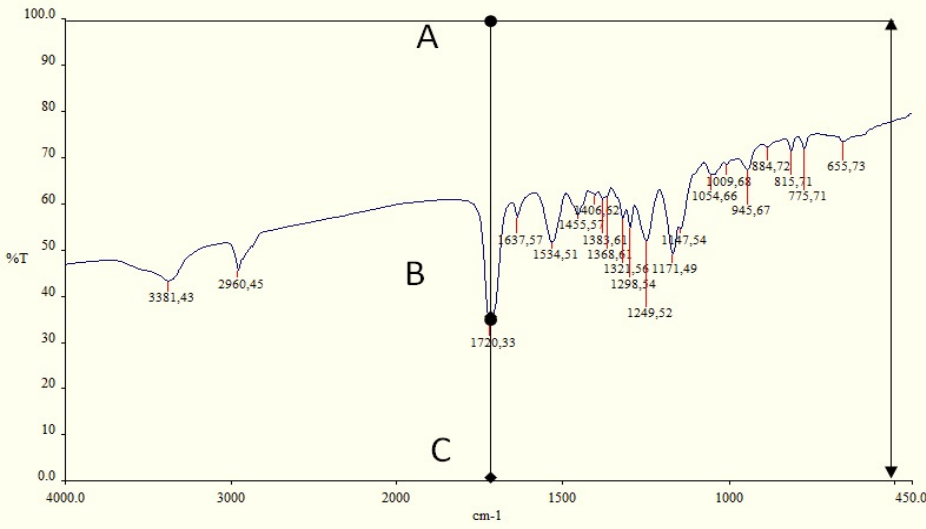

Figure 3. Results of UDMA, ethanol and collagen.

Figure 4 shows the peak of carbonyl ester absorption bands of UDMA at wavenumber absorption $1720 \mathrm{~cm}^{-1}$, the peak of carbonyl absorption bands $(\mathrm{P})$ is calculated using the following formula: $\mathrm{AB}=26 ; \mathrm{BC}=$ $74 ; \mathrm{P}=\mathrm{BC} / \mathrm{AB} \times 100=26 / 74 \times 100=35.13$

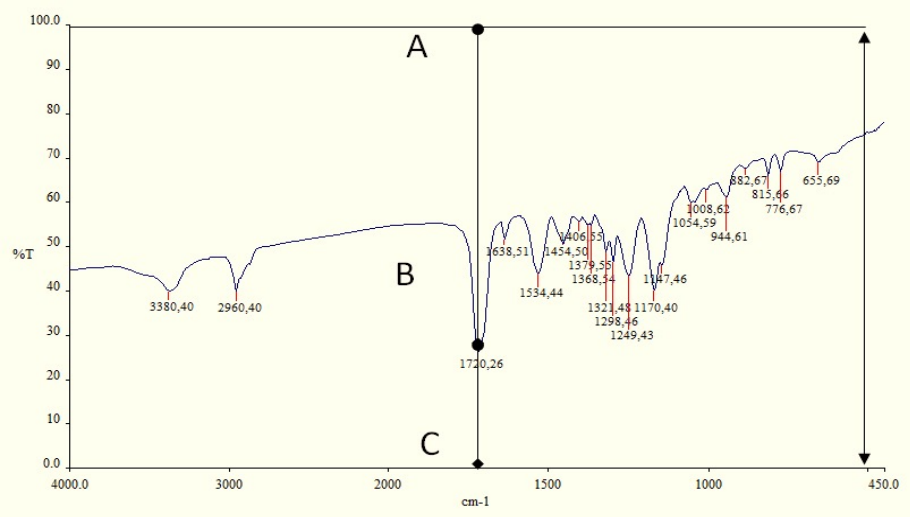

Figure 4. Results of UDMA, acetone and collagen. 
There was a significant difference of peak of carbonyl absorption band between the whole group $(\mathrm{p}<0.05)($ Table 1$)$

Table 1. Mean and standard deviation of peak of the carbonyl absorption bands $(P)$.

\begin{tabular}{ccccc}
\hline Group & N & Mean & SD & p-value* \\
\hline G1 (UDMA and Collagen) & 9 & $110.6^{\mathrm{a}}$ & 9.35 & 0.000 \\
G2 (UDMA, Collagen and Ethanol) & 9 & $52.38^{\mathrm{b}}$ & 8.15 & \\
G3 (UDMA, Collagen and Acetone) & 9 & $25.73^{\mathrm{c}}$ & 3.43 & \\
\hline *One Way ANOVA test; Different letter shows a significant difference. & &
\end{tabular}

*One Way ANOVA test; Different letter shows a significant difference.

Measurement using Tukey HSD was performed to investigate the difference of carbonyl absorption bands between groups. There was a significant difference between UDMA and collagen group, UDMA with collagen and ethanol, and group of UDMA, collagen, and acetone $(\mathrm{p}<0.05)$.

\section{Discussion}

The study of solvent contained in dentin bonding suggested that it has an important role as the dentin bonding penetrates the dentin collagen, considering it has physical and chemical properties that help improve dentin bonding into dentin collagen. The addition of solvent affects the chemical bonds between functional groups in monomers and dentin collagen [1,7].

This research used pure UDMA and solved into acetone and ethanol, considering that the commercially available UDMA may contain any additive materials which may cause potential bias [5,7]. UDMA has characteristics of fully aliphatic homopolymer and chemically and physically cross-linked [13]. UDMA can form both chemical (covalent and hydrogen bonds) and mechanical bond to the dentin, specifically in dentinal collagen.

The limit of this research is, we are unable to get the sample with the same level of clearness during sample making because collagen fibril is an elastic tissue, so it is difficult to grind; this can be overcome by checking the sample mixture with dental explorer, if there is still a lump collagen fibers, grinding is continued until the lump completely mixed and becomes homogeneous. Besides, the other difficulty is the physical properties of UDMA agents that are sticky and the solvent evaporates rapidly; this can be solved by mixing UDMA and solvent first so that the mixture becomes more dilute mixing process should be done more quickly.

The data analysis recorded the peak value of carbonyl absorption bands on dentin collagen between the group of UDMA and collagen, and group of UDMA with collagen and ethanol indicated a significant difference $(\mathrm{p}<0.05)$; this means chemical bonds in UDMA and ethanol is higher than chemical bonds in UDMA and collagen, with the addition of ethanol solvent, it is capable of restoring the collapsed collagen fibril that occurs due to excessive drying because of having large H-bonding capacity. In addition to that, ethanol is able to control the width of the interfibrillar cavity during the evaporation process so that keeping a good diffusion between monomers.

This study's data showed a significant difference between UDMA with collagen group and UDMA and acetone with collagen $(\mathrm{p}=0.000)$. UDMA solved in acetone had a stronger chemical bond. This is probably due to acetone's ability to increase the mixture viscosity, allowing monomer to penetrate into the collagen fibrils.

The study group of UDMA, collagen and ethanol, and UDMA, collagen, and acetone indicated a significant difference $(\mathrm{p}<0.05)$. Ethanol is a protic solvent, a protic solvent is a solvent that forms hydrogen bonds with its solute because formed hydrogen bonds will disrupt the new formed covalent bonds between 
UDMA and collagen so that the bond becomes unstable. Ethanol has a much lower dielectric constant. It is also an improper solvent for its polar solute. When reacted with a polar compound, the hydrogen bond will not be formed and decrease monomer attachment with collagen fibrils [12].

Aside from the drying technique, the solvents contained in dentin bonding also plays a role in composite restoration bond strength. Some solvents characteristics that have an important role in dentin bond strength are hydrogen bonding capacity, vapour pressure, boiling point, dielectric constant, and dipole moment. A study found that monomers used together with solvents have a higher shear strength than those that do not [14-16].

Solvents play an essential role in the process or penetrating dentin bonding to collagen since it acts as water chasers that displace the water and carry the resin monomers into the remineralized dentine $[7,14]$. This is due to the acetone and ethanol solvents having strong evaporation power, which evaporates the moisture content of the dentine surface and penetrates the monomers into collagen fibrils [17]. The evaporation pressure of acetone is high and the remaining water on the dentine surface is reduced, causing the monomer material becomes easier to penetrate into collagen. Meanwhile, ethanol's water-chasing ability is weaker than acetone; considerable amounts of water remains on dentine's surface and cause the monomer material becomes difficult to penetrate into collagen fibrils. The less monomers bind to collagen, the weaker chemical bonds that can cause the adhesive strength decreased [18].

Previous authors showed that dentin bonding with ethanol solvent was able to penetrate deeper into dentin intratubular than those with water solvent [6]. This might be due to ethanol evaporates slower than water; thus, it can carry the adhesive material deeper into the intratubular dentin. The same result was also recorded by Guo et al. [19], which stating that the use of ethanol as solvent can distribute the adhesive material deeper and wider into the intratubular collagen, thus increasing the composite resin attachment. However, adding ethanol to the substance with the carboxyl group may inactivate its chemical activity due to the esterification reaction between the carboxyl group from ethanol and UDMA, specifically in an acid environment. This might impair the adhesive ability [20].

The aromatic group contained in UDMA is hydrophobic and able to neutralize the acidity of carboxyl group. Therefore, the dentin bonding with UDMA is expected to function optimally with acetone as solvent [7]. The solvent may affect the adhesive strength due to the chemical reaction with UDMA resin. Acetone solvent is an aprotic solvent, adding acetone to UDMA may establish a more stable bonds. Acetone solvents do not donate $\mathrm{H}$ atoms so that acetone does not disturb the covalent bonds formed between UDMA and collagen $[11]$.

On the dentin surface, there is water, so that UDMA dentin bonding is difficult to penetrate the collagen fibrils; ethanol has the ability of water chasing so that the amount of water remaining in the dentin is decreased. The ability of water chasing ethanol is lower than that of acetone, so that the evaporation of ethanol is not as big as acetone. This may cause the remaining water in dentine is decreasing; thus, it will be easier for the monomer to penetrate into dentin [12].

\section{Conclusion}

UDMA bonding agents' chemical bonds with acetone solvent are much higher than the chemical bonds between UDMA bonding agents with ethanol solvent on dentin collagen. Further research about the difference in bond strength with different solvents is required. 


\section{Authors' Contributions}

\begin{tabular}{|c|c|c|}
\hline NZ & (D) https://orcid.org/0000-0002-3205-6071 & $\begin{array}{l}\text { Conceptualization, Formal Analysis, Data Curation, Writing - Original Draft, Writing - Review } \\
\text { and Editing, Supervision and Project Administration. }\end{array}$ \\
\hline $\mathrm{RE}$ & (D) https://orcid.org/0000-0003-2939-8983 & $\begin{array}{l}\text { Conceptualization, Methodology, Formal Analysis, Data Curation, Writing - Original Draft, } \\
\text { Writing - Review and Editing and Supervision. }\end{array}$ \\
\hline AS & (iD) https://orcid.org/0000-0002-8632-5492 & $\begin{array}{l}\text { Conceptualization, Formal Analysis, Investigation, Writing - Original Draft and Writing - } \\
\text { Review and Editing. }\end{array}$ \\
\hline TE & (iD) https://orcid.org/0000-0001-8247-7678 & Methodology, Investigation, Writing - Original Draft and Writing - Review and Editing. \\
\hline MIT & (iD) https://orcid.org/0000-0001-8760-7136 & Methodology, Investigation, Writing - Original Draft and Writing - Review and Editing. \\
\hline KK & (iD) https://orcid.org/0000-0001-7015-1523 & $\begin{array}{l}\text { Methodology, Investigation, Writing - Original Draft, Writing - Review and Editing, } \\
\text { Visualization and Project Administration. }\end{array}$ \\
\hline
\end{tabular}

\section{Financial Support}

None.

\section{Conflict of Interest}

The authors declare no conflicts of interest.

\section{Data Availability}

The data used to support the findings of this study can be made available upon request to the corresponding author.

\section{References}

[1] Anusavice KJ, Shen C, Rawls HR. Phillips' Science of Dental Materials. 12th ed. Philadelphia: Saunders; 2012.

[2] Kumar JS, Jayalakshmi S. Bond failure and its prevention in composite restoration - a review. J Pharm Sci Res 2016; $8(7): 627-31$.

[3] Spencer P, Ye Q, Park J, Topp EM, Misra A, Marangos O, et al. Adhesive/dentin interface: the weak link in the composite restoration. Ann Biomed Eng 2010; 38(6):1989-2003. https://doi.org/10.1007/s 10439-010-9969-6

[4] Barszczewska-Rybarek IM. Characterization of urethane-dimethacrylate derivatives as alternative monomers for the restorative composite matrix. Dent Mater 2014; 30(12):1336-44. https://doi.org/10.1016/j.dental.2014.09.008

[5] Ubaldini ALM, Baesso ML, Sehn E, Sato F, Benetti AR, Pascotto RC. Fourier transform infrared photoacoustic spectroscopy study of physicochemical interaction between human dentin and etch-\&-rinse adhesives in a simulated moist bond technique. J Biomed Opt 2012; 17(6):065002. https://doi.org/10.1117/1.JBO.17.6.065002

[6] Shin TP, Yao X, Huenergardt R, Walker MP, Wang Y. Morphological and chemical characterization of bonding hydrophobic adhesive to dentin using ethanol wet bonding technique. Dent Mater 2009; $25(9): 1050-7$. https://doi.org/10.1016/j.dental.2009.03.006

[7] Ekambaram M, Yiu CKY, Matinlinna JP. An overview of solvents in resin-dentin bonding. Int J Adhes Adhes 2015; 57:22-33. https://doi.org/10.1016/j.ijadhadh.2014.09.007

[8] Garcia G, Fernandes KBP, Garcia FCP, D’Alpino PHP, da Rocha Svizero N, Wang L. Solvent retention of contemporary commercial dentin bonding agents in a demineralized dentin matrix. Eur J Dent 2010; 4(3):293-7. https://doi.org/10.1055/s-0039-1697842

[9] Cardoso PC, Lopes GC, Vieira LCC, Baratieri LN. Effect of solvent type on microtensile bond strength of a total-etch one-bottle adhesive system to moist or dry dentin. Oper Dent 2005; 30(3):376-81.

[10] Chen Y, Zou C, Mastalerz M, Hu S, Gasaway C, Tao X. Applications of micro-fourier transform infrared spectroscopy (ftir) in the geological sciences - a review. Int $\mathrm{J}$ Mol Sci 2015; 16(12):30223-50. https://doi.org/10.3390/ijms 161226227

[11] Prasetyo AI, Kunarti S, Soetojo A, Prasetyo EA. Chemical bond strength difference between 4-meta bonding agents with ethanol and acetone solvent on type i collagen. J Int Dent Med Res 2018; 11(2):567-71.

[12] Van Landuyt KL, Snauwaert J, De Munck J, Peumans M, Yoshida Y, Poitevin A, et al. Systematic review of the chemical composition of contemporary dental adhesives. Biomaterials 2007; 28(26):3757-85. https://doi.org/10.1016/j.biomaterials.2007.04.044

[13] Barszczewska-Rybarek IM. A Guide through the dental dimethacrylate polymer network structural characterization and interpretation of physico-mechanical properties: review. Materials 2019; $12(24): 4057$. https://doi.org/10.3390/ma12244057

[14] Jayaprakash T, Srinivasan MR, Indira R. Evaluation of the effect of surface moisture on dentinal tensile bond strength to dentine adhesive: an in vitro study. J Conserv Dent 2010; 13(3):116-8. https://doi.org/10.4103/0972-0707.71640

[15] Normayanti N, Soetojo A, Pribadi N. The difference between residual monomer dentin bonding HEMA and UDMA with acetone and ethanol solvent after binding to type I collagen. Dent J 2018; 51(4):169-72. https://doi.org/10.20473/j.djmkg.v51.i4.p169-172 
[16] Irmak O, Baltacioglu IH, Ulusoy N, Bagis YH. Solvent type influences bond strength to air or blot-dried dentin. BMC Oral Health 2016; 16(1):77. https://doi.org/10.1186/s12903-016-0247-3

[17] Koliniotou-Koumpia E, Kouros P, Koumpia E, Helvatzoglou-Antoniades M. Shear bond strength of a "solvent-free" adhesive versus contemporary adhesive systems. Braz J Oral Sci 2014; 13(1):64-9.

https://doi.org/10.1590/1677-3225v13n1a13

[18] Silva e Souza MH, Carneiro KGK, Lobato MF, Silva e Souza PDAR, de Góes MF. Adhesive systems: important aspects related to their composition and clinical use. J Appl Oral Sci 2010; 18(3):207-14. https://doi.org/10.1590/s1678-77572010000300002

[19] Guo X, Spencer P, Wang Y, Ye Q, Yao X, Williams K. Effects of a solubility enhancer on penetration of hydrophobic component in model adhesives into wet demineralized dentin. Dent Mater 2007; 23(12):1473-81. https://doi.org/10.1016/j.dental.2006.12.003

[20] Zanchi CH, Münchow EA, Ogliari FA, de Carvalho RV, Chersoni S, Prati C, et al. 2011. A new approach in selfetching adhesive formulations: Replacing HEMA for surfactant dimethacrylate monomers. J Biomed Mater Res B Appl Biomater 2011; 99(1):51-7. https://doi.org/10.1002/jbm.b.31871 